\title{
A PROSA-POÉtica de PAUlo FReIRE NA PEDAgogia do OPRIMIdO
}

THE POETIC PROSE IN PAULO FREIRE IN THE PEDAGOGY OF THE OPPRESSED

LA PROSA-POÉTICA DE PAULO FREIRE EN LA PEDAGOGÍA DEL OPRIMIDO

\section{Ana Maria Haddad Baptista ${ }^{1}$ Maurício Pedro da Silva ${ }^{2}$}

RESUMO: Este artigo aborda o livro Pedagogia do Oprimido, de Paulo Freire, a partir do entrecruzamento dos "gêneros" textuais categorizados como prosa e poesia, defendendo a ocorrência, na obra em questão, de uma prosa-poética. Para tanto, seu livro é analisado tanto do ponto de vista da linguagem quanto do ponto de vista do estilo, destacando aspectos discursivos relacionados à criatividade freiriana.

PalavraS-Chave: Paulo Freire. Pedagogia do oprimido. Linguagem. Estilo. Prosa-poética.

ABSTRACT: This article approaches Paulo Freire's Pedagogy of the oppressed, from the intersection of textual "genres" categorized as prose and poetry, defending the occurrence, in this work, of a poetic prose. For this, his book is analyzed both from the point of view of language and the point of view of style, highlighting discursive aspects related to Freirian creativity.

KEYWORDS: Paulo Freire. Pedagogy of the oppressed. Language. Style. Poetic prose.

RESUMEN: Este artículo aborda el libro Pedagogía del Oprimido, de Paulo Freire, a partir del entrecruzamiento de los "géneros" textuales categorizados como prosa y poesía, defendiendo la ocurrencia, en la obra en cuestión, de una prosa poética. Para ello, su libro es analizado tanto desde el punto de vista del lenguaje como desde el punto de vista del estilo, destacando aspectos discursivos relacionados a la creatividad freiriana.

PAlabRAS ClavE: Paulo Freire. Pedagogía del oprimido. Lenguaje. Estilo. Prosa-poética.

\section{ASPECTOS PRELIMINARES}

Desde os finais do século XIX que as tipologias textuais foram, de alguma maneira, bastante questionadas. Sabe-se que inúmeros movimentos de vanguarda, em todas as áreas, contestaram os famosos e clássicos cânones estabelecidos. No Brasil, um dos maiores exemplos de contestação, foi a publicação da famosa obra "Iracema" de José de Alencar. Muito lúcida a singular leitura que Haroldo de Campos (2006) fez da obra em questão. Na verdade, enquanto dezenas de pesquisadores da área, tanto do Brasil como do estrangeiro (em especial, os franceses), se debruçaram para verificar e analisar questões de plágio da obra escrita por Alencar, Haroldo de Campos vai em busca dos elementos de originalidade de "Iracema".

\footnotetext{
${ }^{1}$ Submetido em: 07/01/2019 - Aceito em: 14/01/2019 - Publicado em: 16/01/2019
}

\begin{tabular}{l|l|l|l|l|l|l} 
(C) Rev. Educ. Perspec. & Viçosa, $M G$ & v.9 & n.3 & p.527-537 & set./dez. 2018 & eISSN 2178-8359 \\
\hline
\end{tabular}


Nosso saudoso ensaísta demonstra o quanto a obra de Alencar, no que se refere ao conteúdo, difere em muitos aspectos da obra de Chateaubriand, "Atala", em que a personagem homônima segue as regras estabelecidas pelo seu contexto. Nessa medida, prova-se o caráter transgressor das atitudes de "Iracema", uma das personagens centrais da obra de Alencar: a índia viola as leis de sua tribo para partir com o homem branco e, ainda, lhe dá um filho. Mas tal aspecto não é o mais importante de "Iracema". Na verdade, afirma Haroldo de Campos (2006), o que lhe confere originalidade é o imenso trabalho de pesquisa que Alencar fez para resgatar as expressões do tupi-guarani. Demonstra que a riqueza das vogais da língua lhe confere um caráter muito propício à uma linguagem poética, suave e melódica.

Nessa perspectiva, ainda na esteira de Haroldo de Campos (2006), "Iracema" se destaca por ser um romance-poema. Veja-se, desta forma, que um poema, necessariamente, possui poesia, mas um romance também. $\mathrm{O}$ que seria de um romance sem poesia? Um relatório descritivo ou narrativo. Ou algo semelhante.

Desobedecendo aos cânones estabelecidos pelos clássicos e pela crítica literária de seu tempo, Alencar oferece aos leitores uma obra prima. A predominância de orações justapostas e outros elementos oferecem um lugar singular no contexto do denominado movimento literário romântico brasileiro. Como afirma, o grande crítico, poeta e ensaísta, "Iracema" "desdobra-se em símiles que reproduzem a pressuposta concreção do mundo primitivo" (CAMPOS, 2006, p. 137).

Caso similar ao aqui relatado é o do livro Pedagogia do Oprimido (1968), de Paulo Freire, obra em que os conceitos de prosa e poesia mesclam-se deliberadamente.

Surgido no emblemático ano de 1968, Pedagogia do oprimido, de Paulo Freire, é, pelas injunções da história, um livro de sua época, mas que, tanto pela força-motriz que conduz sua "narrativa" quanto pela profundidade de sua reflexão socioeducativa, ultrapassa o ano em que fora publicado. Desse modo, essa percuciente análise acerca da "grande tarefa humanista e histórica dos oprimidos" (FREIRE, 2005, p. 33) não deixa de dialogar de perto - como era de se esperar de uma obra tão sintonizada com os "acontecimentos" que marcaram a história daquele ano - com toda sorte de ocorrência histórica.

Pode-se dizer que a década de sessenta, de modo geral, foi uma década de transformações de fundo na história do Ocidente, seja pelas alterações no cenário político e cultural mundial, seja pelas mudanças no plano individual, como se verifica em relação ao comportamento e às relações interpessoais, as quais sofreram indiscutíveis mudanças. O ano de 1968, em particular, foi, de toda a década, aquele que mais impacto exerceu nas décadas subsequentes, com seus fatos históricos incontornáveis e com o impulso de renovação que promoveu,

\begin{tabular}{|c|c|c|c|c|c|c|} 
(C) Rev. Educ. Perspec. & Viçosa, $M G$ & v.9 & n.3 & p.527-537 & set./dez. 2018 & eISSN 2178-8359 \\
\hline
\end{tabular}


sobretudo a partir das célebres revoltas de maio de 68, ocorridas, em primeiro lugar, na França, mas logo espalhando-se por vários países, nos cinco continentes.

Não foram poucos, nesse sentido, os "eventos" históricos que marcaram essa década e, em particular, aquele promitente ano de 68. A começar pelas aludidas revoltas de maio, sob o governo de Charles de Gaulle, movimento que se inicia com uma extensa greve na França, resultando na paralisação do sistema de transportes e de comunicação, de fábricas e escolas, do sistema de abastecimento de água e energia. Movimento inspirador de muitos outros acontecimentos posteriores, aquele Maio de 68 - classificado, nas palavras de François Dosse (2017), como um "acontecimento-ruptura" - insuflou uma extensa agenda de reivindicações que, pode-se dizer, não se esgotou até os dias atuais.

Fora uma década de muita violência também, marcada por revoltas, guerras, massacres e invasões. É o que revela o caso emblemático da Guerra do Vietnã, que atinge seu auge justamente por volta de 68, com o massacre de civis em aldeias do Vietnã do Sul e os protestos que se espalhavam, primeiro, por todos os Estados Unidos e, posteriormente, por todo o mundo. No Leste Europeu, foi marcante o episódio conhecido como Primavera de Praga, resultando na inconsequente invasão Tchecoslováquia (atual República Tcheca), pela União Soviética (atual Rússia): ainda em 1968, Alexander Dubček inicia uma série de reformas políticas, sociais, econômicas e culturais na então Tchecoslováquia, o que ocasionaria a invasão soviética e a repressão ao movimento reformista. Finalmente, data desse mesmo ano o não menos dramático Massacre de Tlatelolco, ocorrido no México, em que o exército mexicano reprime violentamente um protesto de estudantes.

São fatos da história que marcaram o ano de 1968 - assim como o assassinato de líderes populares, como Martin Luther King - ou políticos - como Robert Kennedy -, e que fizeram daquele 68 um ano verdadeiramente "explosivo". O Brasil, evidentemente, não ficaria alheio a todos esses acontecimentos: por aqui, vivendo o auge da ditadura militar, tivemos desde eventos como a Passeata dos 100 mil, amplo movimento ocorrido no Rio de Janeiro contra o regime militar, liderado por Vladimir Palmeira, até a aprovação do Ato Institucional n 5 (AI5), assinalando o aumento da repressão militar.

A história, contudo, é feita também por fatos de natureza intelectual, entre a cultura e a produção teórica. Da chamada contracultura à presença assídua de intelectuais no movimento (como é o caso de Sartre e Foucault, entre muitos outros), muito se produziu em termos de cultura e de reflexão teórica naqueles conturbados anos. No Brasil, merece destaque a publicação daquele que se transformaria numa das principais referências teóricas no campo da educação - em especial no da educação popular: A Pedagogia do Oprimido (1968), do pensador e educador pernambucano Paulo Freire.

\begin{tabular}{l|c|c|c|c|c|c} 
(C) Rev. Educ. Perspec. & Viçosa, $M G$ & v.9 & n.3 & p.527-537 & set./dez. 2018 & eISSN 2178-8359 \\
\hline
\end{tabular}




\title{
A PEDAGOGIA DO OPRIMIDO ENTRE O ENSAIO E A POESIA
}

A obra Pedagogia do Oprimido de Paulo Freire destaca-se por ir muito além do que se refere seu conteúdo: a obra em questão, como o próprio autor afirma, é, na verdade, um ensaio. O que é um ensaio? Um ensaio pode ser muitas coisas. Mas sua essência é o espaço de liberdade que lhe é concedido. Liberdade como prática escritural. O conceito de liberdade foi amplamente discutido por Paulo Freire, em especial, no que se refere à Educação. Mas, novamente, o que é um ensaio? Nas palavras do escritor Marco Lucchesi (2017, p. 28):

\begin{abstract}
O ensaio entendido como Unamuno, o ensaio como ensaio, "cujo centro está em toda a parte e a circunferência em parte alguma", como dizem os místicos, e, portanto, suspenso e incompleto como inscrição. O ensaio é um laboratório que ensaia, justamente, e assume todos os riscos, sem medo de enveredar por um caminho cego ou de andar numa rua de mão única, para citar Benjamin. Considero o ensaio como um sonho de olhos abertos, entre rigor e aventura, como quem sonda e perscruta, no verso e no anverso, um tapete persa, e não se dá por satisfeito com o ponto final, porque saber que não cessam os motores de busca. No ensaio pode-se tudo, ou quase tudo, desde que se constitua uma linha discursiva, ao mesmo tempo reta e sinuosa, que se oriente na direção de um não saber, no coração do entusiasmo e do princípio da incerteza. Penso em Octavio Paz e Eduardo Lourenço, em Claudio Magrisou George Steiner. Trata-se de um gênero socrático, prescrito pela farmácia ambígua de Platão, de quem somos herdeiros e órfãos de um sistema incerto de significação.
\end{abstract}

O ensaio, como tão bem define Marco Lucchesi (2017), deveria ser visto como um laboratório. Enfatiza que deve ser responsável pelos riscos. Não se distancia do rigor, no entanto, todo ensaio é corajoso. Desafiador. Ousado. Na verdade, o ensaio compreende uma amplitude sem precedentes. Cremos que o conceito de ensaio estabelecido por Lucchesi vai ao encontro dos objetivos de Paulo Freire ao escrever Pedagogia do Oprimido. Em suas palavras:

\begin{abstract}
As afirmações que fazemos neste ensaio não são, de um lado, fruto de devaneios intelectuais nem, tampouco, de outro, resultam apenas de leituras, por mais importantes que elas nos tenham sido. Estão sempre ancoradas, como sugerimos no início destas páginas, em situações concretas. Expressam reações de proletários, camponeses ou urbanos, e de homem de classe média, que vimos observando, direta ou indiretamente, em nosso trabalho educativo. Nossa intenção é continuar com estas observações para retificar ou ratificar, em estudos posteriores, pontos afirmados neste ensaio. Ensaio que, provavelmente, irá provocar, em algum de seus possíveis leitores, reações sectárias (...) Entre estes, haverá, talvez, os que não ultrapassaram suas primeiras páginas. Uns, por considerarem a nossa posição, diante do problema da libertação dos homens, como uma posição idealista a mais, quando não um 'blá-blá-blá' reacionário. 'Blá-blá-blá' de quem perde tempo falando em vocação ontológica, em amor, em diálogo, em esperança, em humildade, em simpatia (FREIRE, 2016, p. 55).
\end{abstract}

Observe-se que Paulo Freire lança as bases estruturais de seu ensaio. Como ele mesmo afirma, não são "devaneios intelectuais" como poderiam sugerir, talvez, um ensaio. Mas ao

\begin{tabular}{l|l|l|l|l|l|l} 
(C) Rev. Educ. Perspec. & Viçosa, $M G$ & v.9 & n.3 & p.527-537 & set./dez. 2018 & eISSN 2178-8359 \\
\hline
\end{tabular}


mesmo tempo reafirma que suas observações estão baseadas em situações concretas. O "bláblá-blá”, por exemplo, por duas vezes no fragmento citado, é um índice concreto de linguagem que indica um dos pontos de liberdade escritural do autor. Uma expressão muito usada por nós, falantes da língua, no entanto mais usada em situações de oralidade. Em outras palavras: uma expressão que condiz muito mais com o registro coloquial que pende para a ironia (um forte recurso poético e estilístico) de nossa língua.

Contrariando, em muitos aspectos, a linguagem estritamente acadêmica, Paulo Freire, na Pedagogia do Oprimido, pratica um discurso carregado de leveza, de expressões coloquiais. Aspectos que conferem à obra em questão uma proximidade entre o autor e o leitor. Ao mesmo tempo o educador concretiza um estilo. Tal estilo é autoral, único e, finalmente, prova a autonomia escritural e intelectual de Paulo Freire, como veremos adiante. Autonomia, neste ponto, deve-se ser entendido como autonomia de pensamento, de criatividade, daqueles que preservam sua liberdade em todos os sentidos. Quando alguém inaugura um estilo em sua forma de escrever estaria mostrando que existem muitas possibilidades de "se dizer alguma coisa" que não esteja ancorado em modelos pré-fabricados ou instituídos por normas e regras. O ensaio, "gênero" praticado, sabe-se, há séculos, somente pode ser um ensaio porque, entre outros motivos, demonstra um estilo particularíssimo de quem o escreve. Marca única e singular de um certo modo de escrever. Nessa medida, cremos que o escritural de Freire já se aproxima de uma linguagem que contém muitos aspectos de "literariedade" e, como tal, elementos do dizer poético. Da linguagem poética. Uma prosa poética.

\section{DEVIR-OPRIMIDO E A POÉTICA}

Um conceito, de acordo com Gilles Deleuze e Félix Guattari (1992) pode ser criado pela filosofia, pelas artes e pelas ciências. E o mais importante: sem hierarquias. Não há superioridade de "áreas". O que seria um conceito para Deleuze e Guattari? "Todo conceito tem componentes, e se define por eles. Tem, portanto, uma cifra. É uma multiplicidade, embora nem toda multiplicidade seja conceitual" (DELEUZE; GUATTARI, 1992, p. 27). Prosseguem os autores: "Mas, por outro lado, um conceito possui um devir que concerne, desta vez, a sua relação com conceitos situados no mesmo plano" (DELEUZE; GUATTARI, 1992, p. 30).

Cremos que Paulo Freire cria um conceito, se pensarmos juntamente com Deleuze e Guattari, de oprimido. Nas palavras do educador:

O opressor só se solidariza com os oprimidos quando o seu gesto deixa de ser um gesto piegas e sentimental, de caráter individual, e passa a ser um ato de amor àqueles. Quando, para ele, os oprimidos deixam de ser uma designação abstrata e passam a ser os homens concretos, injustiçados e roubados. Roubados na sua 
palavra, por isto no seu trabalho comprado, que significa a sua pessoa vendida (FREIRE, 2016, p. 72).

O fragmento citado coloca um conceito de oprimido que se prolongará e se desdobrará ao longo de Pedagogia do Oprimido. Por que seria um devir-oprimido se pensarmos na fundamentação dos pensadores franceses? Porque para eles um devir não fala para alguém. Um devir não é descrever um alguém. Um devir é, justamente, falar por alguém! Colocar-se no lugar de, como, inclusive, acontece nas grandes obras literárias. Existem diversos devires. Devir-homem. Devir-animal. Devir-mulher. Devir-pedra. E pelos oprimidos o grande educador brasileiro opta por uma linguagem, na obra em questão, cuja predominância está na poética. A estrutura da Pedagogia do Oprimido possui um ritmo, muitas vezes, próximo a uma aceleração furiosa como no seguinte fragmento: "Inauguram a violência os que oprimem, os que exploram, os que não se reconhecem nos outros, não os oprimidos, os explorados, os que não são reconhecidos pelos que os oprimem como outro" (FREIRE, 2016, p. 72).

Este fragmento caberia facilmente numa outra cadeia rítmica, talvez, ditada, por nossos anseios subjetivos: ora mais lentos, ora mais recônditos. Lembramos que mesmo os hermeneutas mais exigentes admitem os ritmos que envolvem um certo grau de subjetividade do leitor:

Inauguram a violência os que oprimem,

os que exploram,

os que não se reconhecem nos outros,

não os oprimidos,

os explorados,

os que não são reconhecidos pelos que os oprimem como outro (FREIRE, 2016, p. 72).

Prossegue Paulo Freire (2016, p. 72):

\footnotetext{
Inauguram o desamor, não os desamados, mas os que não amam, porque apenas se amam.

Os que inauguram o terror não são os débeis, que a ele são submetidos, mas os violentos que, com seu poder, criam a situação concreta em que se geram os "demitidos da vida", os esfarrapados do mundo.

Quem inaugura a tirania não são os tiranizados, mas os tiranos.

Quem inaugura o ódio não são os odiados, mas os que primeiro odiaram.

Quem inaugura a negação dos homens não são os que tiveram a sua humanidade negada, mas os que a negaram, negando também a sua.

Quem inaugura a força não são os que se tornaram fracos sob a robustez dos fortes, mas os fortes que os debilitaram.
}

No fragmento em questão há um desdobramento intenso de uma cadeia de signos que dão a leveza tão necessária e, ao mesmo tempo rigorosa, do poético na linguagem. Orações coordenadas por justaposição. Mas não somente no fragmento em questão. A justaposição dos dizeres de Paulo Freire predominam em Pedagogia do Oprimido. Não custa lembrar

\begin{tabular}{l|l|l|l|l|l|l} 
(C) Rev. Educ. Perspec. & Viçosa, $M G$ & v.9 & n.3 & p.527-537 & set./dez. 2018 & eISSN 2178-8359 \\
\hline
\end{tabular}


que, gramaticalmente, a subordinação está do lado da lógica e de uma abstração em que predominam a objetividade e o racional.

A coordenação, gramaticalmente, é tecida por orações justapostas que por sua vez possibilitam a criatividade, a inventividade e o poético. Dentro do contexto da literatura brasileira, ouvimos em Pedagogia do Oprimido os ressoares de João Cabral de Melo Neto, Graciliano Ramos e Guimarães Rosa. Sons ora metálicos, ora aveludados, que se misturam, em plena harmonia, com a solidez concreta das palavras. Como por exemplo: "desamados", "esfarrapados", "tiranos", "robustez" e tantas outras que poderiam ser citadas.

É o que veremos, a seguir, numa análise da linguagem - mas também do estilo, tal como aludimos aqui de passagem - de sua Pedagogia do Oprimido.

\section{LINGUAGEM E ESTILO EM PEDAGOGIA DO OPRIMIDO}

Analisando essa obra do ponto de vista linguístico, é possível depreender de sua leitura uma série de considerações acerca dos três níveis fundamentais de constituição da linguagem verbal: os níveis fonético-fonológico, morfossintático e semântico-estilístico. Sem querer esgotar o tema - que, tanto por sua natureza quanto pela dimensão que a criatividade linguística adquire na obra de Paulo Freire, parece-nos inesgotável! -, privilegiamos nessa análise, sem prejuízo dos demais aspectos, a construção semântico-estilística do livro em causa, ressaltando seus achados inventivos e inovadores.

É certo, antes de mais nada, que os três níveis estruturais da linguagem, acima aludidos, se inter-relacionam de modo, muitas vezes, indistinto. A título de exemplo, pode-se pensar no quanto o plano lexical repercute nos demais planos (fonológico e estilístico, por exemplo), sobretudo se pensarmos em termos de "criação linguística" - é o caso dos neologismos, categoria lexical recorrente na atividade escritural de Freire (SIMÕES, 2013), responsável, em grande parte por suas escolhas de natureza estilística. Com efeito, segundo Ieda Maria Alves (2007, p. 86, grifos nossos) "a unidade lexical neológica pode ser criada por razões estilísticas e, nesse caso, contribui para causar efeitos intencionais [...] em uma mensagem".

Tratando, como sugerimos há pouco, na construção semântico-estilística de Pedagogia do Oprimido, há que se pensar no texto como uma estrutura linguística comunicativa, sem desconsiderar, por isso mesmo, o contexto em que se insere, uma vez que ambos - texto e contexto - perfazem a dinâmica da articulação textual. Sobre a questão da articulação textual, Elisa Guimarães (1990) ressalta, ainda, a necessidade de se em vista o fato de que um texto não é uma mera sucessão de frases - já que há os "elos transfrásicos" a fazer a ligação entre elas, tornando o texto comunicável -, mas obedece a duas relações diversas: as relações

\begin{tabular}{l|l|l|l|l|l|l} 
(C) Rev. Educ. Perspec. & Viçosa, $M G$ & v.9 & n.3 & p.527-537 & set./dez. 2018 & eISSN 2178-8359 \\
\hline
\end{tabular}


lógicas (responsáveis pela expansão do texto) e as relações de redundância (responsáveis por sua fixação), ambas executando um duplo movimento de antecipação e retroação: "é a rede de relações estabelecida nesse movimento dúplice que permitirá captar o sentido do texto, e distinguir suas unidades constitutivas" (GUIMARÃES, 1990, p. 22).

Atento a tais propriedades do texto escrito, Paulo Freire logrou criar uma obra em que se evidencia a composição lógica e precisa, com cada frase consequente e encadeamento lógico, tanto do ponto de vista da coesão quanto do da coerência discursivas. Daí a série de encadeamentos caracterizados pela repetição de um elemento lexical anterior - e a redundância é elemento fundamental para a fixação do texto enquanto estrutura lógica -, com a função de articular as partes do discurso de modo mais eficaz, conferindo-lhe uma dinâmica que promove uma compreensão imediata de suas ideias.

Assim, se em um parágrafo, o autor afirma não haver "outro caminho senão o da prática de uma pedagogia humanizadora" (FREIRE, 2005, p. 63, grifos nossos), inicia o parágrafo posterior dizendo: "Prática pedagógica em que o método deixa de ser [...]" (FREIRE, 2005, p. 63, grifos nossos), para no parágrafo seguinte afirmar, logo de início: "O método é, na verdade [...]" (FREIRE, 2005, p. 63, grifos nossos). É essa sequência de elementos que se articulam de modo consequente, como dizíamos, que dá ao texto a unidade linguísticoestrutural esperada pelo leitor, fazendo com que assimile melhor a mensagem, por meio de um continuum que se organiza numa relação de anterioridade-posterioridade.

Uma outra característica da maneira como Paulo Freire articula suas estruturas frásicas e oracionais é o emprego - pouco comum - de elementos de coesão (sobretudo as conjunções), em início de parágrafo, o que contribui para a formulação de um discurso mais pausado, com períodos e parágrafos menores. Nesse sentido, não é difícil encontrar em seu texto parágrafos que se iniciam com "na medida em que", "porque", "mas" etc.

Evidentemente, semelhantes arranjos estruturais têm repercussões estilísticas diversas, sempre tendo em vista - a partir da prática da sobriedade vocabular - tanto a clareza quanto a eficácia da mensagem a ser compartilhada. Como lembra Rodrigues Lapa, logo nas primeiras páginas de seu conhecido livro, "no bom estilo não se diz nem de mais nem de menos; diz-se o que é preciso, na medida exata do que se pensa e sente, com vigor e com clareza. E, pecar por pecar, antes pecar por sobriedade do que por inútil sobrecarga de palavras" (LAPA, 1975, p. 8).

Veja-se este exemplo de como Freire, por meio do estilo - considerado aqui numa acepção abrangente, que engloba a clareza e exatidão da mensagem, como quer Lapa, mas também virtuosismo linguístico, por meio de um criativo jogo de palavras e ideias -, consegue criar

\begin{tabular}{l|c|c|c|c|c|c} 
(C) Rev. Educ. Perspec. & Viçosa, $M G$ & v.9 & n.3 & p.527-537 & set./dez. 2018 & eISSN 2178-8359 \\
\hline
\end{tabular}


uma preciosa e poderosa imagem da relação dos educandos com o mundo à sua volta, em benefício da criticidade:

\begin{abstract}
Quanto mais se problematizam os educandos, como seres no mundo e com o mundo, tanto mais se sentirão desafiados. Tão mais desafiados, quanto mais obrigados a responder ao desafio. Desafiados, compreendem o desafio na própria ação de captá-lo. Mas, precisamente porque captam o desafio como um problema em suas conexões com outros, num plano de totalidade e não como algo petrificado, a compreensão resultante tende a tornar-se crescentemente crítica, por isto, cada vez mais desalienada (FREIRE, 2005, p. 80, grifos nossos).
\end{abstract}

É de se destacar, apenas neste pequeno trecho, a maneira como o autor retoma o conceito de desafio/desafiar, a fim de dar sequência ao seu pensamento, complexizando-o e aprofundando-o cada vez mais. Do mesmo modo, o verbo captar é retomado no período, além de se empregarem duas formas da conjunção coordenadas correlatas: tanto/quanto e tão/quanto.

Em matéria de linguagem, não convém falar em estilo ou construção textual sem levar em conta, primeiro, a noção, muito mais ampla e produtiva, de discurso e, em segundo lugar, as incontornáveis relações do discurso com a ideia de poder. Daí, antes de mais nada, nossa tentativa de contextualizar a obra de Paulo Freire no ambiente histórico da década de sessenta, como a marcar a exterioridade em que o discurso freiriano se insere.

De fato, como ensina Eni Orlandi (1996), na relação entre língua e exterioridade, aquela deve ser tomada como sistema significante em sua relação com a história, o que resulta na formação da ideologia: "para que a língua signifique há [...] necessidade da história" (ORLANDI, 1996, p. 28). História e ideologia encontram-se, assim, imbricadas no discurso educacional de Paulo Freire, sobretudo em sua Pedagogia do Oprimido, em que o sentido "político" do texto já se evidencia no próprio título da obra.

Logicamente, como aludimos anteriormente, a noção de poder perpassa, igualmente, todo o texto, uma vez que poder e discurso são conceitos que, via de regra, atuam em conjunto na conformação de uma determinada mensagem, seja ela verbal ou não. Como afirma, com sagacidade, Foucault (2008, p. 10), "o discurso não é simplesmente aquilo que traduz as lutas ou os sistemas de dominação, mas aquilo por que, pelo que se luta, o poder do qual nos queremos apoderar".

Pedagogia do Oprimido é, sem dúvida, um livro em que não apenas as questões históricas e políticas estão envolvidas, como salientamos, mas também o inquebrantável vínculo entre discurso e poder. Como "discurso poderoso" que é, o texto freiriano apresenta-nos uma série de ideias que questiona, critica e reflete sobre nossa sociedade e nossos valores; trata-se, por isso mesmo, de uma narrativa que não apenas discute sobre o poder (o poder do opressor

\begin{tabular}{l|c|c|c|c|c|c} 
(C) Rev. Educ. Perspec. & Viçosa, $M G$ & v.9 & n.3 & p.527-537 & set./dez. 2018 & eISSN 2178-8359 \\
\hline
\end{tabular}


sobre o oprimido, por exemplo), mas se afirma, ela mesma, como um "poder discursivo". Não sem razão, foi e tem sido, historicamente, um texto perseguido, atacado e censurado pelos governos autocráticos e tirânicos.

O poder discursivo consubstancia-se, evidentemente, por meio de uma determinada ideologia - no caso do livro em pauta, não há como negar a presença de uma ideologia que podemos, ainda que provisoriamente, qualificar como "libertária", até pelo fato de se apresentar com um aprofundamento do livro anterior, "Pedagogia como prática da liberdade" (FREIRE, 2005). Promovendo um embate entre uma "ideologia opressora" e uma "ideologia revolucionária" (os termos são do próprio Freire, em sua Pedagogia do oprimido), o autor marca, no discurso mesmo, a tese que busca defender na mensagem veiculada pelo conteúdo textual.

\section{CONSIDERAÇÕES FINAIS}

Consideramos neste texto situar Pedagogia do oprimido enquanto um ensaio renovador e que, de certa forma, demonstra a habitual capacidade de Paulo Freire de se libertar de cânones e regras estabelecidas. $\mathrm{O}$ educador possui um estilo que é caracterizado por um grau bastante singular e, ao mesmo tempo, exemplar de autonomia intelectual e, consequentemente, escritural. Leveza, ritmo e rigor predominam no ensaio em questão. Com tal procedimento Paulo Freire cria um conceito de oprimido. E como foi analisado neste texto dá voz a todos aqueles que são forçosamente oprimidos pela violência simbólica ou não. Dá voz aos verdadeiramente "esfarrapados".

Em Paulo Freire, podemos dizer, ainda que sem o aprofundamento que semelhante afirmação requeira, que, no âmbito da economia das trocas simbólicas bourdieusiana, são as "trocas linguísticas" as que de modo mais saliente assumem o papel ideológico da argumentação, por meio de uma retórica sugestivamente assentada no discours stylistiquement caractérisés (BOURDIEU, 1982).

O que, convenhamos, não é pouco para um autor que considerava "a linguagem do educador ou do político [...] tanto quanto a linguagem do povo, não existe sem um pensar e ambos, linguagem e pensar, sem uma realidade a que se encontrem referidos" (FREIRE, 2005, p. 100).

\section{REFERÊNCIAS}

ALVES, Ieda Maria. Neologismo. Criação lexical. São Paulo: Ática, 2007.

\begin{tabular}{l|c|c|c|c|c|c} 
(C) Rev. Educ. Perspec. & Viçosa, $M G$ & v.9 & n.3 & p.527-537 & set./dez. 2018 & eISSN 2178-8359 \\
\hline
\end{tabular}


BOURDIEU, Pierre. Ce que parler veut dire. L'économie des échanges linguistiques. Paris: Fayard, 1982.

CAMPOS, Haroldo. Metalinguagem \& outras metas: ensaios de teoria e crítica literária. São Paulo: Perspectiva, 2006.

DELEUZE, Gilles, GUATTARI, Félix. O que é a filosofia? Tradução Bento Prado Jr.; Alberto Alonso Muñoz. São Paulo: Editora 34, 1992.

DOSSE, François. A história à prova do tempo: da história em migalhas ao resgate do sentido. São Paulo: Unesp, 2017.

FOUCAULT, Michel. A ordem do discurso. São Paulo: Loyola, 2008.

FREIRE, Paulo. Pedagogia do oprimido. 42 ed., Rio de Janeiro: Paz e Terra, 2005.

FREIRE, Paulo. Pedagogia do oprimido. 60 ed., Rio de Janeiro: Paz e Terra, 2016.

GUIMARÃES, Elisa. A articulação do texto. São Paulo: Ática, 1990.

LAPA, M. Rodrigues. Estilística da Língua Portuguesa. Coimbra: Coimbra, 1975.

LUCCHESI, Marco. Entrevista à Ana Maria Haddad Baptista. Revista Filosofia, n. 129, São Paulo: Editora Escala, 2017.

ORLANDI, Eni Puccinelli. Exterioridade e Ideologia. Cadernos de Estudos Linguísticos, Campinas, n. 30, p. 27-33, jan./jun. 1996.

SIMÕES, Sérgio Lourenço. Pedagogia do neologismo: a linguagem de Paulo Freire e a educação libertadora. 2013. 200 f. Tese (Doutorado em Educação) - Programa de PósGraduação em Educação, Universidade Nove de Julho, São Paulo, SP, 2013.

\section{Sobre os Autores}

1 Ana Maria Haddad Baptista - Doutora em Comunicação e Semiótica (PUC-SP). Professora da Universidade Nove de Julho do programa stricto sensu em Educação. E-mail: professoraanahb@gmail.com - ORCID: https://orcid.org/0000-0003-3468-0158

${ }^{2}$ Maurício Pedro da Silva - Doutor em Letras Clássicas e Vernáculas pela Universidade de São Paulo. Professor na Universidade Nove de Julho (São Paulo). E-mail: maurisil@ gmail.com - ORCID: http://orcid.org/0000-0002-9609-4579 